\title{
AS TIRINHAS NAS AULAS DE LEITURA EM LÍNGUA INGLESA: UMA PROPOSTA DIDÁTICO-PEDAGÓGICA PARA INICIANTES
}

\author{
NÓBREGA, Daniela Gomes de Araújo ${ }^{* *}$ \\ ${ }^{1}$ Universidade Estadual da Paraíba \\ danielanobrega5@gmail.com*
}

\section{RESUMO}

Este artigo traz para discussão a prática e a pedagogia de leitura multimodal nas aulas de leitura em Língua Inglesa para os alunos iniciantes. Este trabalho discute a possibilidade de se trabalhar com o gênero textual "tirinha" em aulas de leitura em língua inglesa. Para tanto, como teoria, para discorrer sobre a noção de gênero, utilizou-se Bazerman (2006); para apresentar as características da linguagem não verbal, recorreu-se a Ekman e Friesen (1969) e Nóbrega (2011); para discutir sobre o gênero textual "tirinha", consideraram-se os trabalhos de Barbosa et al. (2014) e de Ramos e Vergueiro (2015); para debater sobre leitura interativa e multimodal, empregaram-se os subsídios teóricos de Kleiman (2012) e Rojo (2012). Como proposta didático-pedagógica, recomendam-se atividades em sala de aula que associam a leitura multimodal (imagética ou quadrinhista) presente nas "tirinhas" com o texto escrito (diálogos dos personagens), dando ênfase às habilidades orais ou de escrita dos alunos.

PALAVRAS-CHAVE: Ensino de leitura. Língua inglesa.

\section{THE STRIPS IN EFL READING CLASSES: A DIDATIC AND PEDAGOGICAL PROPOSAL FOR BEGINNERS}

\section{ABSTRACT}

This article brings to discussion the practice and pedagogy of multimodal reading in reading classes in English Language for beginners. This paper discusses the possibility of working with the genre "Strips" in reading classes in English Language. To this end, as a theory I used Bazerman (2006) to discuss the notion of gender; to present the characteristics of non-verbal language, it was used Ekman and Friesen (1969) and Nóbrega (2011); to discuss the genre "Strips", it was considered the work of Barbosa et al. (2014), Ramos and Vergueiro (2015); and for the discussion of interactive and multi-modal reading, I used Kleiman (2012) and Rojo (2012). As a didactic and pedagogical proposal, I recommend activities in the classroom that combine multimodal reading (imagery or comic book) present in strips with written text (characters' dialogues), giving emphasis on the learners' oral or written skills. KEYWORDS: Teaching of reading. English.

\section{LAS TIRAS EN LAS CLASES DE LECTURA EN INGLÉS: UNA PROPUESTA EDUCATIVA Y PEDAGÓGICA PARA PRINCIPIANTES}

\section{RESUMEN}

En este artículo se lleva a la práctica la discusión y la pedagogía de la lectura multimodal en clases de lectura en Lengua Inglesa para principiantes. En este trabajo se discute la posibilidad de trabajar con el género "tiritas" en las clases de lectura en Lengua Inglesa. Por lo tanto, como teoría para discutir la noción de género, se utilizó Bazerman (2006); para presentar las características del lenguaje no verbal, se utilizó Ekman y Friesen (1969) y Nóbrega (2011); para discutir el género textual "tirita", se consideraron las obras de Barbosa et al. (2014) y de Ramos y Vergueiro (2015); y, para la discusión de lectura interactiva y multimodal, se recurrió a Kleiman (2012) y Rojo (2012). Como propuesta didáctico-pedagógica, se recomiendan actividades en el aula que combinen la lectura multimodal (imágenes o cómics) presente en tiras con el texto escrito (diálogos de los personajes), con énfasis a las habilidades orales o escritas de los estudiantes.

PALABRAS CLAVE: Educación de lectura. Lengua inglesa. 


\section{CONSIDERAÇÕES INICIAIS}

Se considerarmos que a linguagem não verbal consiste em toda forma não verbal de se comunicar, então o que fazemos enquanto falamos com alguém é, por si só, um ato comunicativo. Os gestos que usamos, o movimento da cabeça, um olhar discreto ou surpreso, por exemplo, podem suscitar inúmeros significados e, impreterivelmente, ajudam-nos a compreender o que e como alguém está querendo nos comunicar algo.

Em sala de aula, também usamos a linguagem não verbal de formas variadas e distintas, e também em momentos diferentes. Quando estamos tirando dúvidas dos nossos alunos, quando nossos discentes nos perguntam algo e quando todos interagem, ora em momentos de descontração, ora em momentos de questionamentos e/ou de explicação de algo, os gestos e o nosso corpo estão falando constantemente; algumas vezes, inclusive, contradizem o que falamos. Tal postura não verbal pode ser explorada em aulas de leitura em língua estrangeira (Inglês), sobretudo quando trabalhamos o gênero textual "tirinhas" com nossos alunos (BARBOSA et al., 2014; RAMOS; VERGUEIRO, 2015).

Inserido nos estudos da Pragmática (LEVINSON, 1983; MEY, 2001), este artigo discorre sobre o uso da linguagem não verbal (imagética ou quadrinhista) nas "tirinhas" e de como nós, professores de língua estrangeira - em nosso caso, de Língua Inglesa -, podemos utilizá-las para auxiliar os discentes nas aulas de leitura. De acordo com Levinson (1983) e Mey (2001), todo tipo de linguagem só pode ser discutida à luz de um determinado contexto. Contexto este que nos proporciona verificar todo tipo de pista, linguística e/ou extralinguística, para buscarmos compreender o uso da linguagem durante qualquer evento comunicativo.

No que tange a analisar a linguagem não verbal/imagética/quadrinhista nas "tirinhas", podemos inferir que tal linguagem só pode ser estudada se verificarmos como os personagens usam as palavras e expressões que eles escolheram, o que estes personagens fazem enquanto falam e a repercussão de suas falas e ações nos outros. Estudar o gênero textual "tirinhas" pela perspectiva não verbal nos permite explorar outros níveis de leitura e, consequentemente, proporcionar aos estudantes irem além das palavras, da leitura puramente verbal. Ler as imagens, as ações e as outras formas semióticas desse gênero rico em significados multimodais 
pode contribuir para melhor entendermos a mensagem das "tirinhas", objeto alvo de discussão neste artigo.

Fruto de um minicurso para a III Jornada do Programa Institucional de Bolsa de Iniciação à Docência (Pibid), da Universidade Estadual da Paraíba (UEPB), Letras-Inglês/2015, este trabalho apresenta e discute a possibilidade de se trabalhar com o gênero textual "tirinha" em aulas de leitura em Língua Inglesa (LI) com turmas de iniciantes.

Assim sendo, este artigo divide-se em seis partes, além desta e das Referências. Na segunda parte, discorremos sobre o conceito mais amplo de gênero textual com base em Bazerman (2006). Na terceira parte, falamos sobre o significado da linguagem não verbal (EKMAN; FRIESEN, 1969), pontuando o aspecto imagético e multimodal que o gênero "tirinha" apresenta. Na quarta parte, apresentamos as características sobre o gênero textual "tirinha". Na quinta parte, discutimos sobre o modelo interativo e multimodal de leitura, trazendo à tona concepções com base em Kleiman (2012) e Rojo (2012). Na sexta parte, apresentamos uma proposta pedagógica que explora o aspecto não verbal (imagético) das "tirinhas" nas aulas de leitura em LI; na sétima parte, por fim, trazemos à tona as considerações finais acerca do estudo.

\section{FALANDO SOBRE GÊNERO TEXTUAL}

Dentre as várias definições de gênero textual de que temos conhecimento, a que usamos neste artigo é a de "[...] padrões comunicativos com os quais as outras pessoas estão familiarizadas, e que elas podem reconhecer mais facilmente o que estamos dizendo e o que pretendemos realizar" (BAZERMAN, 2006, p. 29). Estamos falando aqui de formatos de um evento comunicativo específico, que, segundo esse autor, relaciona-se com situações com as quais as pessoas se familiarizam, isto é, compartilham esse conhecimento. Por exemplo, quando falamos de festa infantil e que tipo de cartão de aniversário precisamos organizar para convidar os amigos, já temos em mente o formato e o tipo de informação que precisamos usar (nome e idade do aniversariante, data e local da festa, além do endereço).

Definimos também os gêneros textuais, também chamados de discursivos, por "características textuais" que nos sinalizam o que eles representam. Essas características textuais nos permitem visualizar a tipologia do texto e o propósito a que o gênero se propõe (BAZERMAN, 
2006). Cartas, e-mails, blogs, contratos, receitas de bolo, histórias em quadrinhos, charges, horóscopos e resenhas, por exemplo, são alguns gêneros textuais que apresentam em sua formatação características diferentes por possuírem objetivos comunicativos distintos. Para ilustrarmos, enquanto as charges transmitem de forma breve mensagens de natureza política com pitadas de humor, as histórias em quadrinhos são mais extensas e podem também apresentar conteúdos de humor.

Além das características textuais, os "[...] gêneros tipificam muitas coisas além da forma textual. São parte do modo como os seres humanos dão forma às atividades sociais" (BAZERMAN, 2006, p. 31). Aqui estamos falando sobre situações sociais e sobre o padrão de acontecimentos dessas situações. Situações do nosso cotidiano, como casamento noturno, festa de aniversário infantil, missa dominical, por exemplo, seguem um determinado padrão de acontecimentos comumente conhecido pelos participantes. Quando conhecemos esses padrões de acontecimento, podemos dizer que os participantes compartilham desse saber. Quando, pelo contrário, os participantes desconhecem o que naturalmente acontece em situações do cotidiano como as aqui mencionadas, dizemos que os participantes desconhecem o que deve acontecer num determinado gênero.

Portanto, (re)conhecer um tipo de gênero textual, como é o caso das "tirinhas", objeto de discussão deste trabalho, possibilita-nos conhecer sobre o propósito comunicativo do gênero e das características textuais que ele apresenta. Com essas informações já conhecidas antes de uma leitura, certamente os alunos que estão começando a aprender inglês como língua estrangeira poderão melhor entender a mensagem que perpassa por aquele gênero. A seguir, apresentamos as características da linguagem não verbal que estão presentes no gênero textual "tirinhas".

\section{A LINGUAGEM NÃO VERBAL E AS TIRINHAS}

Para o antropólogo norte-americano Erving Goffman (2002, p. 19), “[...] muitas das propriedades da fala terão de ser vistas como alternativas a atos extralingüísticos, ou equivalentes funcionais deles". Segundo Goffman (2002), esses gestos funcionais são fundamentais para entendermos o que uma pessoa fala, por exemplo. São esses gestos que "propiciam estados de fala, gestos que policiam esses estados de fala" e, portanto, fazem parte 
da comunicação verbal entre os interlocutores em qualquer evento social. Esses gestos funcionais do qual Goffman tanto fala podem ser vistos na linguagem não verbal, que, impreterivelmente, estão presentes em toda forma de comunicação.

O ato de definir a linguagem não verbal, dentro da perspectiva de Goffman (2002), pode estar relacionado com toda forma não verbal, que vai desde as gravuras, imagens e fotografias até os gestos e expressões faciais que usamos quando nos comunicamos. Esse tipo de linguagem, contudo, também pode ser compreendido por meio de várias categorias. Dentro dos estudos da linguagem não verbal, podemos citar: (1) a proxêmica, (2) a cinésica, (3) a tacsênica, (4) o estudo do toque e do olhar e (5) a paralinguagem.

A proxêmica é o estudo dentro da linguagem não verbal que lida com a distância entre os interlocutores e o grau de relacionamento que determinadas distâncias podem determinar. Por exemplo, podemos verificar que, numa situação formal vista entre um médico e um paciente numa clínica, a distância entre os dois não é tão próxima como a de dois amigos que estão almoçando. Numa clínica médica, por exemplo, o profissional de Medicina normalmente atende ao paciente apertando inicialmente a mão dele de forma educada, pedindo-lhe para sentar e depois começa a verificar o estado de saúde dele. Tal comportamento revela, nessa situação, a não aproximação afetiva e apenas um contato profissional. A proxêmica, portanto, também pode pesquisar o grau de afetividade entre as pessoas através da distância que elas adotam em suas relações (EKMAN; FRIESEN, 1969; NÓBREGA, 2011).

Por sua vez, a cinésica estuda os movimentos corporais relativos à fala. Nesse tipo de estudo, podemos analisar aspectos tais como os gestos, o movimento do corpo, as expressões faciais, o contato dos olhos, o sorriso. Todas essas expressões podem revelar emoções importantes que tanto podem complementar, monitorar ou contradizer a fala (referências). Ao complementar a fala, por exemplo, o sorriso pode nos revelar alegria e satisfação. Isso pode ser constatado numa pesquisa em sala de aula. Descrevendo e analisando o sorriso dos alunos em trabalhos em grupos, Nóbrega (2011) verificou que esse sorriso pode sinalizar satisfação dos educandos em compartilhar uma tarefa e, consequentemente, a produção oral em Língua Inglesa pode ser mais vista.

Embora não tão vistos e pesquisados, a tacsênica e o comportamento do olhar (eye contact) também merecem destaque. $\mathrm{O}$ olhar tende a ser investigado para analisarmos como os 
interlocutores sinalizam interesse ou ausência de interesse na relação, aproximação ou falta de aproximação e consequente afetividade (EKMAN; FRIESEN, 1969; NÓBREGA, 2011).

A tacsênica, entretanto, estuda o toque nas relações sociais e a consequente implicação no grau de aproximação entre as pessoas numa dada situação social (EKMAN; FRIESEN, 1969; NÓBREGA, 2011). Tal aspecto pode ser visto se analisarmos as relações entre professor e alunos nos países orientais, a exemplo de China e Japão. Entre docente e discentes, nessas duas nações, por exemplo, normalmente existe uma relação um pouco distante e pouco uso do toque, denotando educação e respeito para com o outro. Esse tipo de relação já é visto de maneira diferente entre professor e alunos nos países ocidentais, como no Brasil. O toque entre as pessoas nas relações sociais no Brasil, por sua vez, traz uma conotação de aproximação e afetividade. $\mathrm{O}$ estudo da tacsênica, portanto, traz à tona questões sobre afetividade nas relações, as quais também merecem ainda mais pesquisas no contexto de sala de aula.

Sobre a paralinguagem, podemos dizer que essa categoria estuda os sons vocais. Esse estudo inclui o ritmo, tom de voz, entonação e estresse, isto é, são os aspectos suprassegmentais da fala. De acordo com Gumperz (1982), esses aspectos paralinguísticos que estão presentes na fala podem indicar certas posturas e posições sociais dos interlocutores, revelando, assim, suas condutas diante de outros que os estão vendo. São, pois, esses aspectos da linguagem não verbal que sinalizam quando alguém está sendo irônico quando fala algo que não condiz com a verdade; quando alguém está mentindo ou dizendo a verdade; ou até quando alguém está traindo. $\mathrm{O}$ tom de voz, por exemplo, pode indicar determinadas posturas que podem aproximar ou afastar as pessoas. A pessoa tida como autoritária ou mandona tende a apresentar uma postura rígida, com um tom de voz severo e rouco. Ou seja, o tom de voz pode sinalizar as intenções e sentimentos dos interlocutores no ato de fala (EKMAN; FRIESEN, 1969; NÓBREGA, 2011).

Portanto, ao lermos as "tirinhas", todos esses aspectos da linguagem não verbal que foram citados até aqui podem e devem ser explorados em aulas de leitura em Língua Inglesa. Nos gêneros imagéticos, como as "tirinhas", o ato de ler implica entender o que e como os personagens estão falando, como eles estão interagindo entre si e o modo como eles veiculam várias formas de língua(gem). Cabe ao leitor estar atento para toda forma multimodal da linguagem nesse gênero discursivo, tais como as expressões faciais dos personagens, o movimento corporal, o olhar, além 
de outras formas não verbais mostradas pelos personagens nas "tirinhas". A seguir, apresentamos, de forma breve, as características do gênero textual "tirinhas".

\section{AS TIRINHAS}

O gênero textual "tirinhas" tem sido denominado e discutido a partir de um gênero textual maior, ou hipergênero: as histórias em quadrinhos (HQs). Portanto, falar sobre as "tirinhas" nos remete também às HQs.

Inicialmente criada nos Estados Unidos, a "tirinha", ou tira de jornal, surgiu devido à falta de espaço nos jornais para a publicação dos passatempos. Por ser de natureza híbrida e curta, isto é, por conter aspectos textuais orais e escritos e ser apresentado de forma sequenciada, esse gênero caiu no gosto dos leitores de jornal. Além disso, as "tirinhas" possuem outra característica bem peculiar que atrai seus leitores: humor nas estórias (BARBOSA et al., 2014; RAMOS; VERGUEIRO, 2015).

O fato de unir o texto escrito informal com as imagens faz com que esse gênero não somente atraia o público infantojuvenil, inicialmente público-alvo desse tipo de gênero, mas também o grupo adulto, por apresentar características da realidade por um viés mais bem-humorado. Como Ramos e Vergueiro (2015, p. 11) explicam, os gêneros híbridos, como as "tirinhas", charges e HQs, "[...] são dispositivos visuais gráficos que veiculam e discutem aspectos da realidade social, apresentando-a de forma crítica e com muito humor".

Assim como as HQs, as "tirinhas" possuem uma linguagem informal, diálogos curtos e recursos icônico-verbais próprios (balões, onomatopeias, metáforas visuais, figuras cinéticas) que possibilitam o leitor unir a imagem ao texto escrito oralizado pelos personagens, facilitando, dessa forma, a compreensão da leitura. Além dessas peculiaridades, o conteúdo temático das "tirinhas" é bem diversificado, geralmente associado às questões da realidade social. Temas tais como ecologia, reciclagem, proteção ao planeta Terra são abordados nos gibis e/ou "tirinhas" da Turma da Mônica, por exemplo (VARGAS; MAGALHÃES, 2011).

O uso das "tirinhas" em aulas de leitura, de forma geral, tem sido bastante explorado, tanto que o Exame Nacional do Ensino Médio (Enem) no Brasil (BARBOSA et al., 2014; RAMOS; VERGUEIRO, 2015) tem também usado nas provas com o intuito de o aluno-leitor explorar o 
recurso não verbal/imagético como estratégia de leitura. Conforme Barbosa et al. (2014, p. 32) argumentam, as tirinhas "[...] se apresentam como uma sequência de quadros que trazem uma mensagem ao leitor, normalmente uma narrativa, seja ela ficcional ou real". Essas sequências, portanto, possibilitam o leitor fazer associações entre o que está verbalizado de forma escrita com o que está sendo exposto de forma não verbal/imagética, representado ora pelas ações dos personagens, ora pela descrição do contexto da estória.

Para este trabalho, o uso das "tirinhas" nas aulas de leitura em LI possui dois objetivos. O primeiro uso está relacionado a atrair o interesse na leitura em LI por ser um gênero multimodal - apresenta uma variedade de linguagens a ser usada pelo leitor. Isto é, concordando com o que Rojo (2012, p. 19) explica sobre multiletramentos, o gênero "tirinha" é híbrido e multimodal por apresentar "[...] textos compostos de muitas linguagens e que exigem capacidades e práticas de compreensão e produção de cada uma delas (multiletramentos) para fazer significar". Na leitura de "tirinhas", o aluno-leitor precisa associar a leitura das imagens, cores, movimentos corporais dos personagens com o texto escrito (diálogo dos personagens) em sequência, isto é, de quadro em quadro. Essa leitura sequencial e de modos (linguagens) diferentes permite ao aluno-leitor perceber que um tipo de linguagem pode auxiliar na compreensão da estória como um todo, uma vez que um tipo de linguagem pode ajudar na compreensão de outro tipo de linguagem.

O segundo objetivo em usar esse gênero nas aulas de leitura está em associar as habilidades da língua em vários momentos da aula. Em uma aula, por exemplo, o professor pode associar a leitura silenciosa com a escrita, ou seja, a leitura pode servir como a habilidade inicial e insumo para motivar os discentes a escreverem outras estórias. Em outro momento, o docente pode usar a leitura em voz alta para trabalhar a pronúncia e a entonação dos diálogos, propiciando também a dramatização com os educandos; uma alternativa eficiente para desenvolver a produção oral dos alunos. Por ser um gênero de várias semioses, isto é, de linguagens diferentes em um único espaço (ROJO, 2012), a leitura passa a ser vista como um processo interativo que exige do leitor uma capacidade em interagir dinamicamente com o texto, assunto que será tema da próxima seção. 


\section{CONCEPÇÃO INTERATIVA E MULTIMODAL DE LEITURA}

Dentre os modelos e/ou concepções de leitura que a teoria nos apresenta (ascendente, descendente e interativo), o modelo interativo ou sociointerativo de leitura é o que mais se enquadra para se trabalhar com as "tirinhas" nas aulas de leitura em LI.

Nessa concepção de leitura, as operações cognitivas usadas geralmente por um leitor proficiente são aquelas que privilegiam o conhecimento prévio, conhecimento linguístico, conhecimento enciclopédico, conhecimento textual e conhecimento léxico-estrutural (KLEIMAN, 2012). O conhecimento prévio diz respeito ao conhecimento de mundo e das experiências já vividas pelo leitor; o conhecimento linguístico envolve tanto o lexical e o estrutural, isto é, são conhecimentos sobre o significado das palavras e da morfossintaxe da língua; e o conhecimento textual se refere ao conhecimento tanto dos tipos de texto (narrativo, descritivo, dissertativo e injuntivo) como dos gêneros textuais que circulam em várias situações comunicativas do cotidiano. Todas as operações necessárias para se ativar todos os conhecimentos aqui já citados são usadas na leitura de "tirinhas". Quando, por sua vez, um desses conhecimentos não é de conhecimento do leitor, o professor precisa fazer uso do recurso não verbal/imagético para auxiliar na leitura da "tirinha".

$\mathrm{Na}$ leitura multimodal, o processo de ler e compreender o que se lê não é muito diferente da concepção interativa apresentada anteriormente. Uma prática multimodal ou multissemiótica de leitura envolve uma leitura de diversidade de linguagens situadas num único espaço. Por exemplo, a leitura na internet é uma leitura multimodal, haja vista incluir a leitura do texto escrito, de imagens, sons, cores, às vezes movimentos, áudios e links (ROJO, 2012).

Para esse tipo de leitura, exigem-se novas práticas de leitura chamadas de multiletramentos, pois são necessários novos conhecimentos para ler e compreender o que se lê. Ao lermos "tirinhas", precisamos ter consciência dessa diversidade de linguagens presente nesse gênero. Imagens, cores, onomatopeias, diálogos, expressões faciais dos personagens são alguns exemplos de linguagens encontradas nas "tirinhas". Saber como usá-las para beneficiar a compreensão requer um prática multimodal, isto é, demanda uma consciência multissemiótica do leitor: associar as várias formas de linguagem ao texto escrito. 
Por sua vez, na concepção interativa de leitura, todo o conhecimento (de mundo, de língua, de imagem) é usado para processar a leitura. No desconhecimento de um, outro tipo de conhecimento pode ser acionado. Por exemplo, ao ler uma "tirinha", o aluno-leitor, por desconhecer certas palavras, pode usar a imagem e a situação da estória para ajudá-lo a inferir o significado de uma determinada palavra. Para ilustrar, podemos verificar o uso desses conhecimentos com a "tirinha" da Turma da Mônica, a seguir.

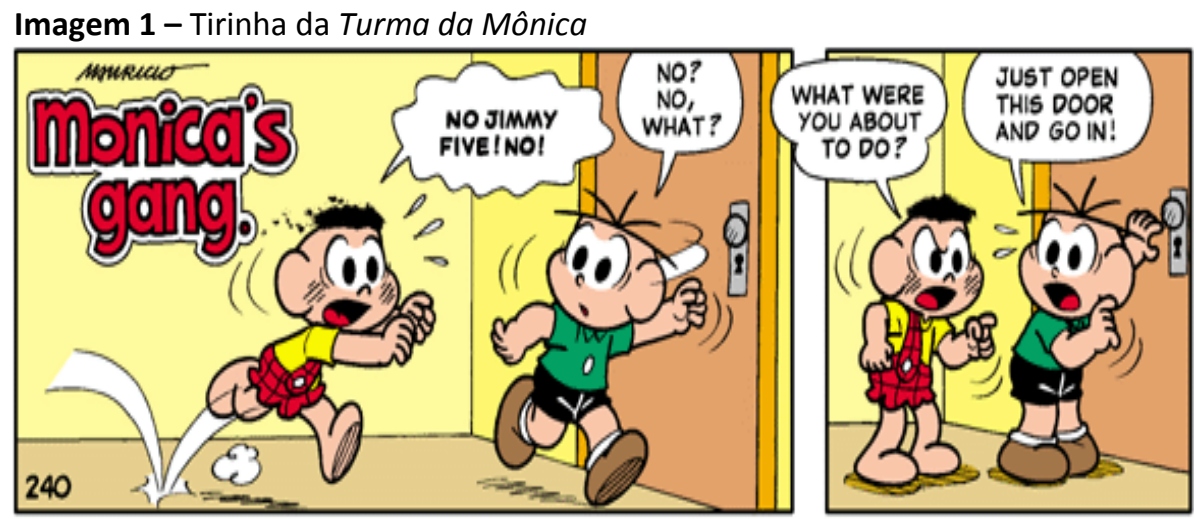

Fonte: Mauricio de Sousa.

Nessa "tirinha", o aluno-leitor, sobretudo o iniciante de Língua Inglesa, pode desconhecer o verbo frasal "go in" na estória. Em contrapartida, esse mesmo aprendiz pode conhecer o tipo de situação que os personagens estão vivenciando. Esses conhecimentos, o de mundo e o de situação, podem auxiliar o leitor a tentar compreender o que significa "go in". Nesse caso, foram acionados o conhecimento prévio do aluno-leitor - ao analisar a situação e o conhecimento das ações dos personagens - ao analisar o que os personagens fazem na estória. Esses dois tipos de conhecimentos podem ser usados como ferramentas auxiliares no processamento da leitura por ajudar na inferência de significado de palavras desconhecidas.

A concepção de leitura aqui processada foi, primeiro, a interativa, porque dois tipos de conhecimentos foram acionados para auxiliar o aluno-leitor na compreensão da estória/tirinha: o de mundo e o linguístico. A segunda concepção foi a multimodal, pelo fato de o aluno-leitor ter de associar as ações (movimento corporal e expressões faciais) dos personagens Cebolinha e Cascão com o diálogo usado por eles. Esse conjunto de conhecimentos - escritos, gestuais, faciais e de mundo - está impreterivelmente situado numa prática multimodal e interativa, prática essa cada vez mais exigida na sociedade contemporânea do século XXI. 


\section{TIRINHAS EM AULAS DE LEITURA EM LÍNGUA INGLESA: UMA PROPOSTA DE LEITURA}

Na leitura de "tirinhas", a leitura não verbal (multimodal) é constantemente requerida, fazendo com que o leitor assuma uma leitura sequencial, de quadro em quadro, e considerando também todos os aspectos envolvidos nas quadros (cores, movimento corporal dos personagens, onomatopeias, olhares, expressões faciais, etc.). Essa leitura imagética ou, nas palavras de Kress e Theo van Leeuwen (1998), as estruturas visuais, isto é, imagens, realizam significados, assim como a leitura de estruturas linguísticas também o fazem.

Usadas como um recurso pedagógico, as imagens das "tirinhas" podem ser empregadas de formas variadas numa aula de leitura em LI que enfatiza o desenvolvimento das estratégias de leitura. Na parte de pré-leitura, por exemplo, podemos explorar as imagens como forma de chamar a atenção dos alunos-leitores à situação em que a estória ocorre. Nesse momento, podemos recorrer às ações dos personagens, o que eles estão fazendo, a forma como eles estão dispostos e como eles interagem. Na "tirinha", cada sequência evidencia um significado que leva a sequência seguinte a formar um significado global. Na "tirinha" abaixo, mostraremos como a fase da pré-leitura pode ser feita.

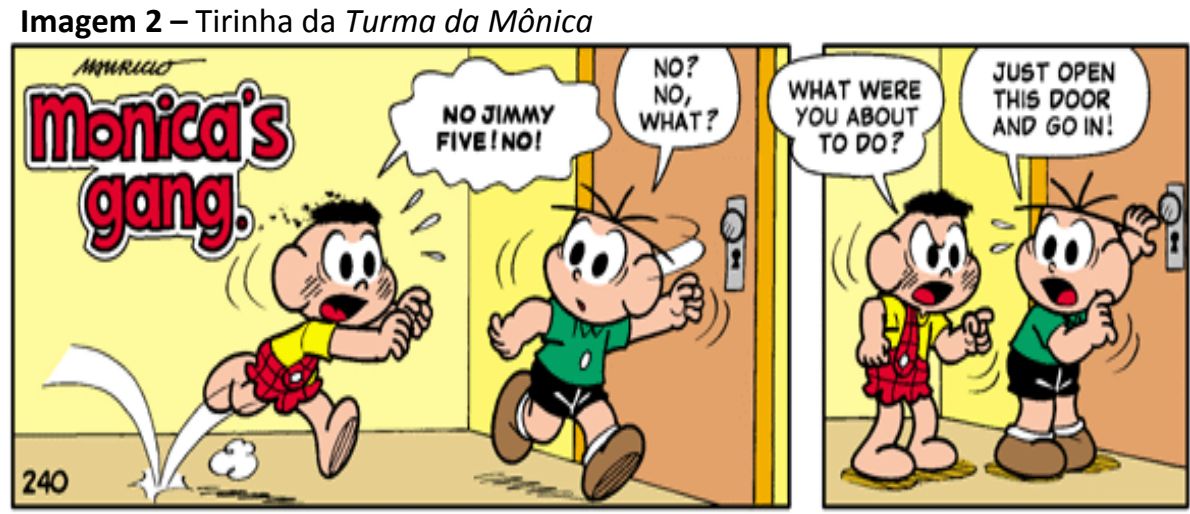

Fonte: Mauricio de Sousa.

Nessa tira, o personagem Cascão (Smudge) está chamando a atenção de Cebolinha (Jimmy Five) correndo em direção a ele. Tal ação - correr em direção a ele - está também vinculada à expressão facial de Cascão, que sugere que Cebolinha não deve fazer algo, expresso por sua fala: "No[,] Jimmy Five! No!". Nessa primeira sequência, as expressões faciais de Cascão e 
de Cebolinha - de surpresa - parecem sinalizar que o assunto trazido por Cascão não é dos melhores; há algo estranho que pode (ou não) acontecer.

Ainda nessa mesma sequência, podemos unir a imagem - nesse caso, as expressões faciais de Cascão e de Cebolinha - à fala dos dois personagens. Daí surge a conexão entre imagem e palavras/frases/expressões, ou seja, a imagem com o texto escrito. Típico de gêneros híbridos, o texto oral acrescenta ou complementa informações ao texto visual, dando maior visibilidade à construção global da sequência narrativa (BARBOSA et al., 2014; RAMOS; VERGUEIRO, 2015). Nesse processo de compreender o que está se passando na "tirinha", cabe ao leitor interpretar estes dois veículos de informação - visual e escrito.

Como alternativa de atividade de leitura, a habilidade oral também pode ser explorada com leituras orais. Considerando que as falas nas "tirinhas" são exemplos típicos de textos orais informais, isto é, falas do cotidiano infantil, podemos utilizá-las para explorar o uso de gírias e/ou outras expressões típicas de fala em detrimento da linguagem escrita formal, mais encontradas em gêneros textuais escritos, como artigos científicos, resenhas, monografias, etc. Ainda nesse aspecto em se trabalhar com a habilidade da fala, nas "tirinhas" podemos explorar as características das falas dos personagens em conjunto com as estruturas gramaticais usadas por eles. Frases curtas, verbos no imperativo, verbos frasais, tais como o encontrado na "tirinha" anterior - "No, what? Just open this door and go in!" -, podem ser ensinados a fim de que os alunos-leitores possam depois criar suas próprias estórias como atividade de sala ou de casa.

Outra forma de se trabalhar com as "tirinhas" em sala de aula, sobretudo com crianças, pode envolver a habilidade da escrita com desenhos. Nesse momento, estamos trabalhando com a fase da pós-leitura, fase esta em que nós, professores, avaliamos o que os alunos-leitores aprenderam na leitura do referido gênero. Solicitar aos discentes para desenharem o que eles entenderam ou para elaborarem uma estória com desenhos pode ser uma maneira de incentivá-los a criarem outras estórias a partir do que eles previamente leram. Essa concepção de leitura pode estimular os alunos-leitores a (re)criarem estórias outras, fazendo com que tomem consciência de que toda estória tem conexão com outras estórias.

Essa noção de intertextualidade (KLEIMAN, 2012), presente em qualquer texto (oral ou escrito), a exemplo dos textos que (re)criamos, pode desenvolver nos alunos-leitores a consciência 
de que todo tipo de conhecimento - textual, linguístico, de mundo, imagético e multimodal interage em prol de um propósito maior: o de leitura de mundo, que, como já afirmava Paulo Freire, antecede a leitura de palavras. Essa concepção de leitura, levada para a sala de aula, pode desenvolver nos alunos-leitores de LI a concepção crítica de leitura, fazendo com que desenvolvam a leitura multissemiótica como o pontapé inicial para a leitura do texto escrito.

\section{CONSIDERAÇÕES FINAIS}

De acordo com o que foi apresentado e discutido neste capítulo, pode-se inferir que trazer à tona para a aula de leitura em Língua Inglesa (LI) com iniciantes uma visão multimodal (imagética ou quadrinhista) de leitura possibilita aos educandos perceberem esse tipo de linguagem com outros olhos. $\mathrm{O}$ ato de ler e compreender uma língua estrangeira - em nosso caso, a LI - não está apenas associado a ler e a entender o vocabulário e a estrutura linguística contidos no texto escrito. Assim como fazemos na leitura em língua materna, de forma geralmente automática, podemos orientar nossos discentes a lerem as imagens, fotos ou qualquer outro tipo de linguagem não verbal quando estiverem acompanhando os textos escritos. Fazendo isso, estamos motivando nossos discentes a exercitarem leituras de modos diferentes, leituras essas que nos conscientiza sobre a leitura que fazemos, de forma involuntária, em nosso cotidiano. Afinal de contas, antes de lermos o que está escrito no papel, somos educados desde cedo a ler o mundo a nosso redor, cheio de cores, formas, sons e movimentos. Essa é a proposta didático-pedagógica que permeia este trabalho.

\section{REFERÊNCIAS}

BARBOSA, A. et al. (Org.). Como usar as histórias em quadrinhos na sala de aula. 4. ed. São Paulo: Contexto, 2014.

BAZERMAN, C. Gêneros textuais, tipificação e interação. In: BAZERMAN, C.; DIONíSIO, A. P.; HOFFNAGEL, J. C. (Org.). Gêneros textuais, tipificação e interação. 2. ed. São Paulo: Cortez, 2006. p. 19-46.

EKMAN, P.; FRIESEN, W. The repertoire of nonverbal behavior: categories, origins, usage and coding. Semiótica, 1, 1969. Disponível em: <www.paulekamn.com/publications/jounal-articlesbook-chapters/>. Acesso em: 5 jan. 2010. 
GOFFMAN, E. A situação negligenciada. In: RIBEIRO, B. T.; GARCEZ, P. M. (Org.). Sociolingüística interacional: antropologia, lingüística e sociologia em análise do discurso. 2. ed. São Paulo: Loyola, 2002. p. 13-20.

GUMPERZ, J. J. Convenções de contextualização. In: RIBEIRO, B. T.; GARCEZ, P. M. (Org.). Sociolingüística interacional: antropologia, lingüística e sociologia em análise do discurso. Porto Alegre: AGE, 1998. p. 98-119.

KLEIMAN, A. Oficina da leitura: teoria e prática. 14. ed. Campinas: Pontes, 2012.

KRESS, G.; van LEEUWEN, T. Reading images: the grammar of visual design. Routledge: London, 1998.

LEVINSON, S. C. Pragmatics. Cambridge: Cambridge University, 1983.

MEY, J. L. Pragmatics: an introduction. 2. ed. Oxford: Blackwell, 2001.

NÓBREGA, D. G. A. A fala do professor e o sorriso dos alunos na sala de aula em Língua Inglesa. In: BERGSLEITHNER, J. M.; WEISSHEINER, J.; MOTA, M. B. (Org.). Produção oral em LE: múltiplas perspectivas. Campinas: Pontes, 2011. p. 261-290.

RAMOS, P.; VERGUEIRO, W. Quadrinhos na educação: da rejeição à prática. São Paulo: Contexto, 2015.

ROJO, R. Pedagogia dos multiletramentos. In: ROJO, R.; MOURA, E. (Org.). Multiletramentos na escola. São Paulo: Parábola, 2012. p. 11-31.

VARGAS, S. L.; MAGALHÃES, L. M. O gênero tirinhas: uma proposta de sequência didática. Educação em Foco, Juiz de Fora, v. 16, n. 1, p. 119-143, 2011.

Recebido em 21 de julho de 2016.

Aceito em 18 de setembro de 2016. 